\title{
Avaliação do efeito fisiológico da farinha de semente de abóbora (Cucurbita maxima, L.) no trato intestinal de ratos
}

\author{
Evaluation of the pumpkin (Cucurbita maxima, L.) seed flour effects on the intestinal tract of rats \\ Matilde PUMAR ${ }^{1}$, Maria Cristina Jesus FREITAS ${ }^{2 *}$, Priscila Machado de CERQUEIRA ${ }^{3}$, \\ Sabrina Barreiros SANTANGELO ${ }^{3}$
}

\begin{abstract}
Resumo
O presente trabalho teve por objetivo avaliar o efeito fisiológico da Farinha de Semente de Abóbora (FSA) no trato intestinal de ratos Wistar machos recém desmamados, submetidos a dietas experimentais contendo Farinhas de Semente de Abóbora (FSAs) integral, peneirada e residual, por 10 dias. As dietas experimentais foram obtidas substituindo-se $30 \%$ do valor total de amido e dextrina, da ração controle, pela FSA correspondente. As farinhas e rações controle e experimentais foram caracterizadas quimicamente. Os animais divididos em grupos foram avaliados quanto ao crescimento, consumo, material fecal e $\mathrm{pH}$ cecal. As FSAs e rações experimentais apresentaram relevantes teores de fibras alimentares, proteínas e lipídios. Dietas contendo FSAs integral, peneirada e residual levaram a um ganho ponderal e ingestão similar entre todos os grupos. Em relação ao grupo controle, os animais experimentais submetidos a dietas contendo FSAs apresentaram maior volume e peso fecais $(\mathrm{p}<0,05)$, além de significativa excreção de fibra insolúvel, em especial o grupo FSA residual. Apenas a FSA residual proporcionou queda $(\mathrm{p}<0,05)$ do $\mathrm{pH}$ cecal. Os resultados obtidos indicam o potencial da FSA como fonte de fibra e sua capacidade em atuar aumentando peso e volume fecal, promovendo laxação.

Palavras-chave: fibra alimentar; farinha de semente de abóbora; ratos.
\end{abstract}

\begin{abstract}
This study has the aim to evaluate the physiological effects of the Pumpkin Seed Flour (PSF) on the intestinal tract of newly weaned male Wistar rats fed on diets containing whole Sifted and Residual - PSF for ten days. The experimental diets were prepared substituting $30 \%$ of the total content of starch and dextrin of the control diet for the corresponding PSF. The control and the experimental diets were chemically characterized. The animals were divided into four groups in order to evaluate growth, ingestion, feces, and cecal $\mathrm{pH}$. The PSFs and the experimental diets presented high contents of alimentary fibers, proteins, and lipids. Similar ingestions of diets containing whole Sifted and Residual - PSF resulted in body weight gain. Rats on diets containing PSFs showed higher feces volume and weight $(\mathrm{p}>0.05)$ in addition to an expressive insoluble fiber excretion, especially in the Residual - PSF group. Only the Residual PSF presented a significant reduction $(\mathrm{p}<0.05)$ in the cecal pH. These results indicate the PSFs potential as a fiber source and its ability to increase the fecal weight and volume promoting a laxative effect.

Keywords: alimentary fiber; pumpkin seed flour; rats.
\end{abstract}

\section{Introdução}

A promoção e a manutenção da saúde estão intimamente ligadas à nutrição humana. Assim, uma dieta balanceada produz equilíbrio nutricional e bem-estar ao indivíduo. Entretanto, o hábito alimentar da população vem sofrendo modificações ao longo dos anos e tais alterações levaram ao baixo consumo de fibras alimentares (MONDINI; MONTEIRO, 1994).

A reduzida ingestão de fibra alimentar (FA) vem sendo associada ao aumento de inúmeras doenças crônicas não transmissíveis (RODRÍGUEZ et al., 2006), enquanto o seu alto consumo se relaciona à prevenção de diversas patologias. Os efeitos proporcionados pela FA se devem a sua composição e às propriedades físicas e químicas dos polissacarídeos presentes, bem como dos biocompostos associados a esta fração (JENKINS et al., 2004; SCHNEEMAN, 1999).
A atuação fisiológica da fibra alimentar, dentre outros fatores, se relaciona a sua solubilidade em água. De acordo com a solubilidade, elas podem ser classificadas em solúveis (pectinas, gomas e mucilagens) e insolúveis (celulose, hemicelulose e lignina). Assim, as frações insolúveis da FA não são, de maneira geral, fermentadas e exercem mais uma ação física sobre o intestino, aumentando o volume e o peso fecal, acelerando o trânsito intestinal, estimulando os movimentos peristálticos e melhorando a consistência fecal (PACHECO; SGARBIERI, 2001).

Devido aos benefícios da FA e em função de seu baixo consumo, a indústria alimentícia vem se utilizando de fontes alternativas vegetais com o intuito de fornecer produtos mais saudáveis e ricos em fibras. Em conseqüência, sementes de várias espécies se tornaram recursos alternativos para a alimentação humana, mostrando-se excelentes alternativas naturais de fibras

Recebido para publicação em 30/11/2007

Aceito para publicação em 17/7/2008 (002250)

${ }^{1}$ Laboratório de Tecnologia de Alimentos, Departamento de Nutrição Básica e Experimental, Universidade do Estado do Rio de Janeiro - UERJ, Rio de Janeiro - RJ, Brasil

${ }^{2}$ Nutrição Básica e Experimental, Ciência e Tecnologia de Alimentos, Universidade Federal do Rio de Janeiro - UFRJ, CEP 21940-590, Cidade Universitária,

Ilha do Fundão - RJ, Brasil, E-mail: cristina@nutricao.ufrj.br

${ }^{3}$ Instituto de Tecnologia dos Alimentos, Universidade Federal Rural do Rio de Janeiro - UFRRJ, Rio de Janeiro - RJ, Brasil

${ }^{*}$ A quem a correspondência deve ser enviada 
alimentares (DEL-VECHIO et al., 2005; GIUNTINI; LAJOLO; MENEZES, 2003).

Estudos mostram que a semente de abóbora apresenta alto teor de fibras alimentares, além de ser relativa fonte protéica e apresentar alto percentual de óleos poliinsaturados (ESUOSO et al., 1998; SAMANT; REGE, 1989; YOUNIS; GHIRMAY; SHIHRY, 2000). Efeitos benéficos da semente de abóbora sobre o metabolismo, fisiologia e nutrição humana também foram encontrados (EL-ADAWY; TAHA, 2001; MANSOUR et al., 1993).

Considerando o elevado teor de fibra alimentar da semente de abóbora e ciente de todos seus efeitos benéficos à saúde, o presente trabalho teve por objetivo avaliar o efeito fisiológico da Farinha de Semente de Abóbora (FSAs) no trato intestinal de ratos jovens.

\section{Material e métodos}

\subsection{Obtenção das farinhas de semente de abóbora (FSAs)}

Para a realização do estudo foram utilizadas sementes de abóboras baianas (Cucurbita maxima, L.) provenientes da Central de Abastecimento do Estado do Rio de Janeiro (CEASA-RJ). As Farinhas de Semente de Abóbora (FSAs) foram obtidas conforme fluxograma da Figura 1.

Após elaboração, as Farinhas de Semente de Abóbora (FSAs) foram acondicionadas, separadamente, em sacos etiquetados, selados e mantidas sob refrigeração até a sua utilização na elaboração das rações e análises.

\section{Análise química das FSAs}

A fibra alimentar nas FSAs foi determinada pelo método de Van Soest (1963), modificado por Mendez et al. (1985). As análises de umidade, cinzas e proteína bruta foram realizadas de acordo com o Instituto Adolfo Lutz (1985). O fator de multiplicação para o nitrogênio titulado foi de 5,7 (JONES, 1941). Os lipídios foram determinados através da extração de éter etílico em aparelho de Soxhlet, de acordo com o Instituto Adolfo Lutz (1985), e os glicídios calculados por diferença das demais análises (NIFEXT). O valor calórico total foi calculado empregando-se os seguintes fatores: 4 para proteínas e carboidratos e 9 para lipídios.

\subsection{Elaboração das rações}

Foram elaboradas quatro rações, uma controle e três experimentais. A ração controle foi elaborada de acordo com Reeves, Nielsen e Fahey (1993) para dieta de manutenção, e as rações experimentais modificadas foram obtidas substituindose $30 \%$ do valor total de amido e dextrina, da ração controle, pela farinha de semente de abóbora correspondente, conforme Tabela 1.

\section{Análise da composição química das rações}

A composição química das rações foi estimada utilizandose rótulos dos produtos, tabela de composição de alimentos

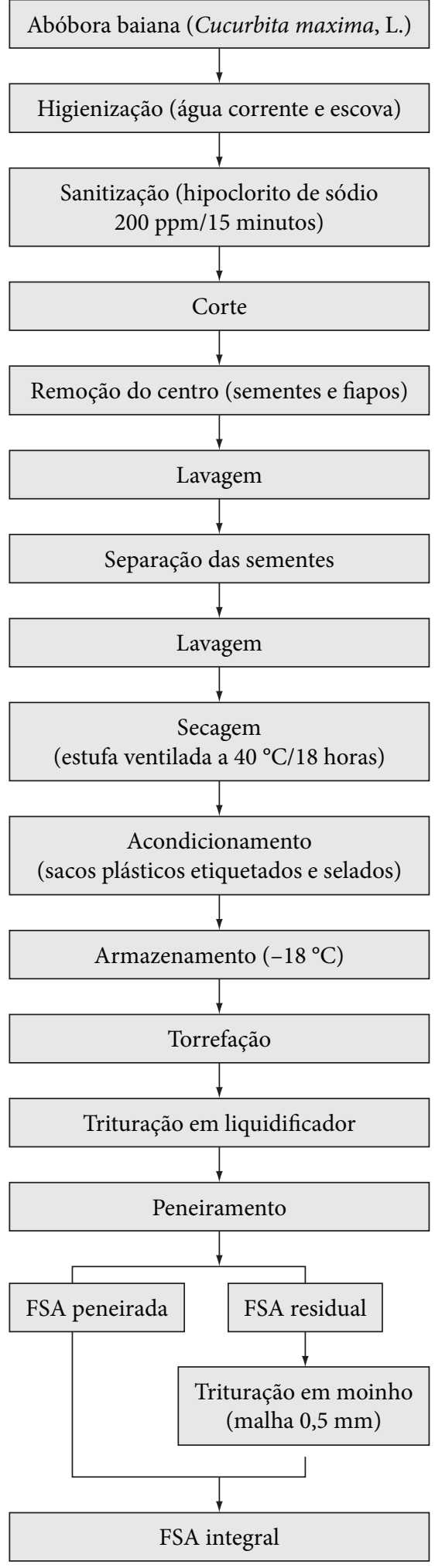

Figura 1. Fluxograma para obtenção das Farinhas de Semente de Abóbora (FSAs).

(PHILIPPI, 2002) e dados obtidos das análises químicas realizadas nas Farinhas de Semente de Abóbora (FSAs). O valor calórico total foi calculado, empregando-se fator 4 para proteínas e carboidratos e fator 9 para lipídios. 
Tabela 1. Formulação das rações controle e experimentais.

\begin{tabular}{|c|c|c|c|c|}
\hline \multirow{3}{*}{$\begin{array}{l}\text { Componentes } \\
\text { (g.kg-1 de ração) }\end{array}$} & \multicolumn{4}{|c|}{ Rações ${ }^{1}$} \\
\hline & \multicolumn{4}{|c|}{ Experimentais farinha de semente de abóbora } \\
\hline & Controle & Integral & Peneirada & Residual \\
\hline Amido de milho ${ }^{\mathrm{a}}$ & 465,7 & 325,9 & 325,9 & 325,9 \\
\hline Dextrina $^{2}$ & 155,0 & 108,6 & 108,6 & 108,6 \\
\hline FSA & - & 186,2 & 186,2 & 186,2 \\
\hline Caseína ${ }^{\mathrm{b}}$ & 140,0 & 140,0 & 140,0 & 140,0 \\
\hline Sacarose & 100,0 & 100,0 & 100,0 & 100,0 \\
\hline Óleo de soja & 40,0 & 40,0 & 40,0 & 40,0 \\
\hline $\begin{array}{l}\text { Celulose microcrislina }{ }^{c} \\
\text { (fibra) }\end{array}$ & 50,0 & 50,0 & 50,0 & 50,0 \\
\hline Mistura mineral $^{\mathrm{d}}$ & 35,0 & 35,0 & 35,0 & 35,0 \\
\hline Mistura vitamínica $^{e}$ & 10,0 & 10,0 & 10,0 & 10,0 \\
\hline L-cistina $^{\mathrm{f}}$ & 1,8 & 1,8 & 1,8 & 1,8 \\
\hline Bitartarato de colina ${ }^{g}$ & 2,5 & 2,5 & 2,5 & 2,5 \\
\hline
\end{tabular}

${ }^{1}$ Reeves et al. (1993); ${ }^{2}$ Maizena ${ }^{\circ}$; e,b,c,d,e,f,g Obtidas no Comércio e Indústria Farmos LTDA.

\subsection{Ensaio biológico}

Animais

Foram utilizados 20 ratos machos da linhagem Wistar, recém desmamados, provenientes do Laboratório de Nutrição Experimental (LABNE) da Universidade Federal Fluminense. Os animais inicialmente receberam dieta comercial e quando alcançaram peso variando de 110 a $125 \mathrm{~g}$ foram distribuídos em 4 grupos com peso médio semelhante, passando, então, a receber dietas controle e experimentais por 10 dias. Durante o estudo os ratos permaneceram alocados em gaiolas de polipropileno individuais cobertas com maravalhas e o biotério foi mantido sob temperatura média de $21^{\circ} \mathrm{C}$, com alternância de período de 12 horas de claro-escuro.

Os ratos tiveram acesso livre à dieta e à água. $\mathrm{O}$ peso corporal (PC) e a quantidade de ingestão (I) foram tomados a cada 48 horas, correspondendo aos tempos experimentais $\mathrm{T} 1$, T2, T3, T4 e T5.

\section{Material fecal}

Os peletes fecais, coletados de cada animal no intervalo de 48 horas, foram pesados em balança digital, secos em estufa a $50{ }^{\circ} \mathrm{C}$ por 48 horas, pesados novamente e, só então, acondicionados em sacos plásticos codificados e armazenados em temperatura ambiente. Posteriormente, foram processados em triturador e a fração fibra insolúvel foi analisada.

Análise da fração fibra insolúvel

A fração Fibra Detergente Neutro (FDN), que expressa fibra insolúvel, foi determinada pelo método Van Soest (1963) no material fecal coletado nos tempos experimentais T1 e T5.

\section{Análise morfológica}

As análises morfológicas do material fecal (MF) foram efetuadas em microscópio eletrônico de varredura (MEV) seguindo a técnica descrita por Haddad et al. (1998). As micrografias obtidas foram arquivadas em disquetes para avaliação.

\section{Cécum e material cecal}

Após o término do período de experimento os animais foram sacrificados e tiveram o cécum retirado para pesagem em balança digital. O material cecal fresco igualmente foi pesado e teve seu $\mathrm{pH}$ determinado em peagâmetro.

Determinação do $\mathrm{pH}$ do material cecal

Realizada por processo eletrométrico empregando-se o potenciômetro adaptado para determinação, de acordo com o Instituto Adolfo Lutz (1985).

\subsection{Análise estatística}

Todos os parâmetros quantificados no estudo, exceto o morfológico, foram avaliados por análise de variância (ANOVA) e teste de Tukey com nível de confiança de 95\%, utilizando-se o software Statistical versão 6.0 (PIMENTEL-GOMES, 1984).

\section{Resultados e discussão}

\subsection{Composição química das farinhas de semente de abóbora (FSAs)}

Os valores de análise da composição química das farinhas de semente de abóbora (Tabela 2) evidenciaram relevantes teores de fibras insolúveis, proteína e lipídios. Teores consideráveis desses macronutrientes e de fibras alimentares também foram encontrados em outros tipos de sementes vegetais (MATUDA; MARIA NETO, 2005; MOURE et al., 2004; VALLILO et al., 2001).

A diferença entre os valores percentuais de proteína, lipídios e fibra insolúvel nas FSAs integral, peneirada e residual pode ser atribuída aos diferentes tipos de processamento sofrido por cada farinha (Figura 1). Assim, a manutenção do endosperma das sementes para elaborar as FSAs integral e peneirada justifica o maior teor de lipídios e proteína destas farinhas. Já a FSA residual por ser composta basicamente pelo tegumento, ou seja, a casca da semente de abóbora, rica em fibra insolúvel, teve este componente se destacando $(\mathrm{p}<0,05)$ em relação às demais farinhas.

\subsection{Características das rações}

Conforme Tabela 3, o teor de fibra alimentar se destacou para as três rações experimentais contendo FSAs, especialmente, para a FSA residual.

As rações também apresentaram Valor Energético (VET) semelhante, fornecendo quantidades suficientes de macro e micronutrientes para o desenvolvimento dos animais, o que pode ser confirmado ao se avaliar o ganho ponderal dos animais durante o experimento (Figura 2).

\subsection{Peso corpóreo e ingestão dos animais}

Os animais dos grupos controle e experimentais apresentaram médias de peso semelhantes, demonstrando desempenho quanto ao crescimento ponderal durante todos os tempos experimentais (Figura 2). Igualmente, não houve diferença 
Tabela 2. Composição química das Farinhas de Semente de Abóbora (FSAs).

\begin{tabular}{lccc}
\hline \multirow{2}{*}{ Componentes (\%) } & \multicolumn{3}{c}{ Farinhas de Semente de Abóbora (FSAs) } \\
\cline { 2 - 4 } & Integral & Peneirada & Residual \\
\hline Umidade & $8,41^{\mathrm{a}}$ & $7,80^{\mathrm{b}}$ & $9,68^{\mathrm{c}}$ \\
Cinzas & $4,32^{\mathrm{a}}$ & $4,27^{\mathrm{a}}$ & $3,19^{\mathrm{b}}$ \\
Proteína & $26,79^{\mathrm{a}}$ & $28,37^{\mathrm{b}}$ & $26,77^{\mathrm{a}}$ \\
Lipídios & $32,25^{\mathrm{a}}$ & $32,96^{\mathrm{a}}$ & $20,35^{\mathrm{b}}$ \\
Fibra insolúvel & $29,49^{\mathrm{a}}$ & $24,88^{\mathrm{a}}$ & $47,52^{\mathrm{b}}$ \\
Carboidratos totais $^{1}$ & - & 1,72 & - \\
Kcal (\%) & 397,41 & 417,00 & 290,23 \\
\hline
\end{tabular}

Médias seguidas de letras iguais na mesma linha se assemelham estatisticamente entre si a $5 \%$; e ${ }^{1}$ Calculado por diferença.

Tabela 3. Composição nutricional das rações controle e experimentais contendo FSAs.

\begin{tabular}{|c|c|c|c|c|}
\hline \multirow{3}{*}{$\begin{array}{l}\text { Componentes } \\
\text { g. } 100 \mathrm{~g}^{-1} \text { de ração }\end{array}$} & \multicolumn{4}{|c|}{ Rações $^{1}$} \\
\hline & \multirow[t]{2}{*}{ Controle } & \multicolumn{3}{|c|}{$\begin{array}{l}\text { Experimental farinha de } \\
\text { semente de abóbora }\end{array}$} \\
\hline & & Integral & Peneirada & Residual \\
\hline Proteína & 14,4 & 18,7 & 19,0 & 18,7 \\
\hline Lipídios & 4,3 & 10,3 & 10,4 & 8,1 \\
\hline Carboidratos totais & 71,8 & 53,9 & 54,2 & 53,9 \\
\hline Fibra alimentar & 5,0 & 10,5 & 9,6 & 13,8 \\
\hline Mistura mineral & 3,5 & 3,5 & 3,5 & 3,5 \\
\hline Mistura vitamínica & 1,0 & 1,0 & 1,0 & 1,0 \\
\hline Valor energético (kcal) & 383,5 & 383,1 & 386,4 & 363,3 \\
\hline
\end{tabular}

${ }^{1}$ Reeves et al. (1993).

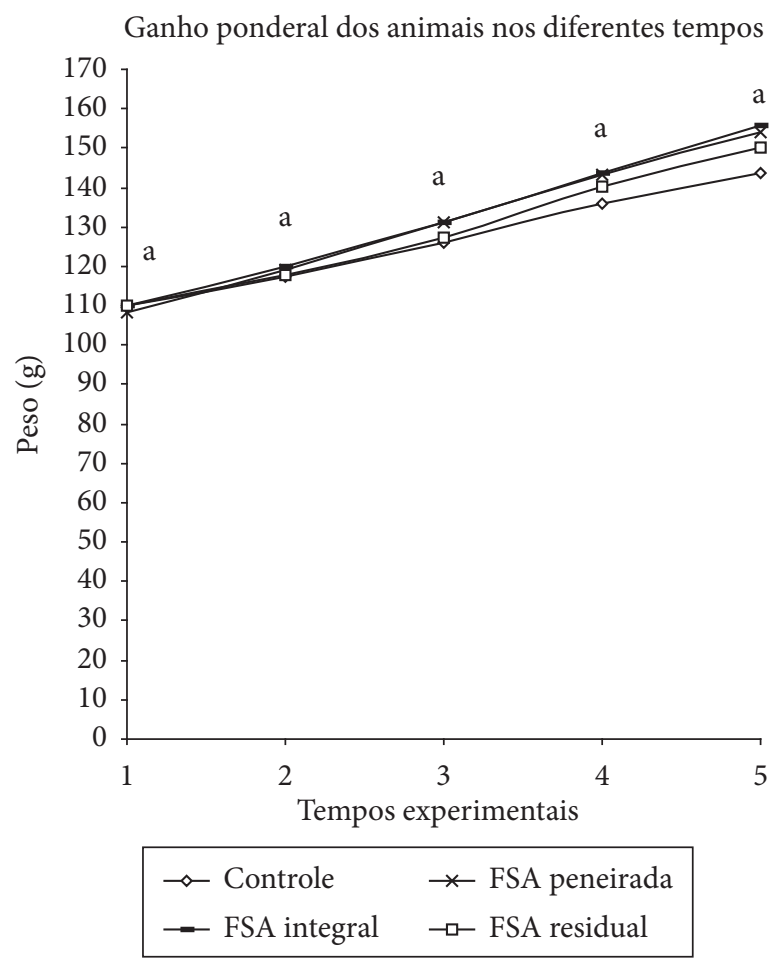

Figura 2. Médias do Peso Corporal (PC) dos grupos de animais nos diferentes tempos de experimento. Letras iguais acima das linhas indicam que não se houve diferença significativa entre os grupos $(p>0,05)$. significativa para a ingestão das rações entre todos os grupos estudados, conforme Tabela 4.

Tais resultados evidenciaram que a incorporação das farinhas de semente de abóbora, como fonte de fibra alimentar, não foi capaz de interferir no ganho de peso corporal e consumo dos animais.

\subsection{Análise do peso e determinação química do material fecal}

Os animais que receberam rações com FSAs apresentaram maior peso fecal $(p<0,05)$ em relação aos animais do grupo controle (Tabela 5).

A fibra alimentar é o principal componente dietético capaz de exercer influência sobre o peso das fezes, assim, o aumento do peso fecal para os grupos experimentais está diretamente relacionado ao conteúdo aumentado de fibras insolúveis das rações experimentais acrescidas de farinhas de semente de abóbora (Tabela 3). As fibras insolúveis tendem a apresentar maior resistência ao processo fermentativo, exercendo efeito físico e de retenção de água à massa fecal (FREITAS et al., 2004).

Apesar da predominante semelhança $(p>0,05)$ entre o peso das fezes dos animais submetidos às três rações experimentais, o grupo que recebeu ração com FSA residual apresen-

Tabela 4. Médias do consumo de ração entre os grupos de animais estudados.

\begin{tabular}{ccccc}
\hline Tempos & \multicolumn{3}{c}{ Consumo de ração dos grupos $(\mathrm{g})$} \\
\cline { 2 - 5 } experimentais & Controle & \multicolumn{3}{c}{$\begin{array}{c}\text { Experimental farinha de } \\
\text { semente de abóbora }\end{array}$} \\
\cline { 2 - 4 } & & $25,100^{\mathrm{a}}$ & $26,70^{\mathrm{a}}$ & $26,70^{\mathrm{a}}$ \\
\cline { 2 - 5 } T1 & $20,30^{\mathrm{a}}$ & $27,80^{\mathrm{a}}$ & $27,10^{\mathrm{a}}$ & $28,30^{\mathrm{a}}$ \\
T2 & $28,00^{\mathrm{a}}$ & $29,50^{\mathrm{a}}$ & $28,90^{\mathrm{a}}$ & $30,40^{\mathrm{a}}$ \\
T3 & $27,50^{\mathrm{a}}$ & $28,00^{\mathrm{a}}$ & $28,50^{\mathrm{a}}$ & $28,20^{\mathrm{a}}$ \\
T4 & $27,20^{\mathrm{a}}$ & $28,90^{\mathrm{a}}$ & $28,30^{\mathrm{a}}$ & $29,10^{\mathrm{a}}$ \\
T5 & $31,00^{\mathrm{a}}$ &
\end{tabular}

Médias seguidas de letras iguais na mesma linha não diferem estatisticamente entre si a $5 \%$.

Tabela 5. Médias do peso úmido e seco dos peletes fecais nos diferentes tempos.

\begin{tabular}{|c|c|c|c|c|c|}
\hline \multirow{3}{*}{$\begin{array}{c}\text { Tempos } \\
\text { experimentais }\end{array}$} & \multirow{3}{*}{ Fezes } & \multicolumn{4}{|c|}{ Teor de fezes dos grupos (g) } \\
\hline & & \multirow[t]{2}{*}{ Controle } & \multicolumn{3}{|c|}{$\begin{array}{c}\text { Experimental farinha de } \\
\text { semente de abóbora }\end{array}$} \\
\hline & & & Integral & Peneirada & Residual \\
\hline \multirow[t]{2}{*}{$\mathrm{T} 1$} & Úmido & $3,0^{\mathrm{a}}$ & $5,2^{\mathrm{b}}$ & $5,8^{\mathrm{b}}$ & $6,0^{\mathrm{b}}$ \\
\hline & Seco & $2,3^{\mathrm{a}}$ & $4,2^{\mathrm{b}}$ & $4,1^{\mathrm{b}}$ & $5,0^{\mathrm{b}}$ \\
\hline \multirow[t]{2}{*}{$\mathrm{T} 2$} & Úmido & $2,9^{\mathrm{a}}$ & $5,3^{\mathrm{b}}$ & $5,4^{\mathrm{b}}$ & $6,5^{\mathrm{b}}$ \\
\hline & Seco & $2,3^{\mathrm{a}}$ & $4,4^{\mathrm{bc}}$ & $4,0^{\mathrm{b}}$ & $5,3^{\mathrm{c}}$ \\
\hline \multirow[t]{2}{*}{$\mathrm{T} 3$} & Úmido & $2,9^{\mathrm{a}}$ & $5,6^{\mathrm{b}}$ & $5,4^{\mathrm{b}}$ & $6,5^{\mathrm{b}}$ \\
\hline & Seco & $2,1^{\mathrm{a}}$ & $4,4^{\mathrm{bc}}$ & $4,0^{\mathrm{b}}$ & $5,3^{\mathrm{c}}$ \\
\hline \multirow[t]{2}{*}{$\mathrm{T} 4$} & Úmido & $3,0^{\mathrm{a}}$ & $5,2^{\mathrm{b}}$ & $5,8^{\mathrm{b}}$ & $6,0^{\mathrm{b}}$ \\
\hline & Seco & $2,5^{\mathrm{a}}$ & $4,8^{\mathrm{b}}$ & $4,5^{\mathrm{b}}$ & $5,2^{\mathrm{b}}$ \\
\hline \multirow[t]{2}{*}{ T5 } & Úmido & $2,9^{\mathrm{a}}$ & $6,2^{b}$ & $5,8^{\mathrm{b}}$ & $7,0^{\mathrm{b}}$ \\
\hline & Seco & $2,2^{\mathrm{a}}$ & $4,9^{\mathrm{bc}}$ & $4,5^{\mathrm{b}}$ & $5,5^{c}$ \\
\hline
\end{tabular}

Médias seguidas de letras diferentes na mesma linha diferem estatisticamente entre si a $5 \%$ pelo teste de Tukey. 
tou aumento, chegando a $15 \%$ em relação aos demais grupos experimentais.

Semelhante efeito de subprodutos ricos em fibra insolúvel sobre o trato intestinal tem sido relatado na literatura (RAUPP et al., 2000; 2004).

Ainda com relação às características do material fecal, o grupo experimental apresentou fezes visivelmente mais compactas e com maior volume. Tanto os animais do grupo controle quanto os experimentais não apresentaram muco envolvendo seus peletes fecais.

A síntese de muco pelos enterócitos e os metabólitos produzidos pelas bífido bactérias em processo fermentativo confere maior umidade às fezes (CANDIDO; CAMPOS, 1995). Conforme a Figura 3, os valores percentuais de umidade da matéria fecal não diferiram entre si $(\mathrm{p}>0,05)$.

Os percentuais de umidade fecal encontrados para os animais experimentais podem estar relacionados com a presença marcante da fração fibra insolúvel nas dietas contendo FSAs. Ao que tudo indica, estas frações sofreram pouca fermentação e a absorção de água durante a sua passagem pelo trato intestinal não interferiu na umidade final das fezes $(p>0,05)$.

Analisando quimicamente as fezes excretadas pelos animais, verifica-se que a excreção da fração de fibra insolúvel (Tabela 6) foi significativamente maior para o grupo experimental em relação ao controle.

Média dos percentuais de umidade-material fecal

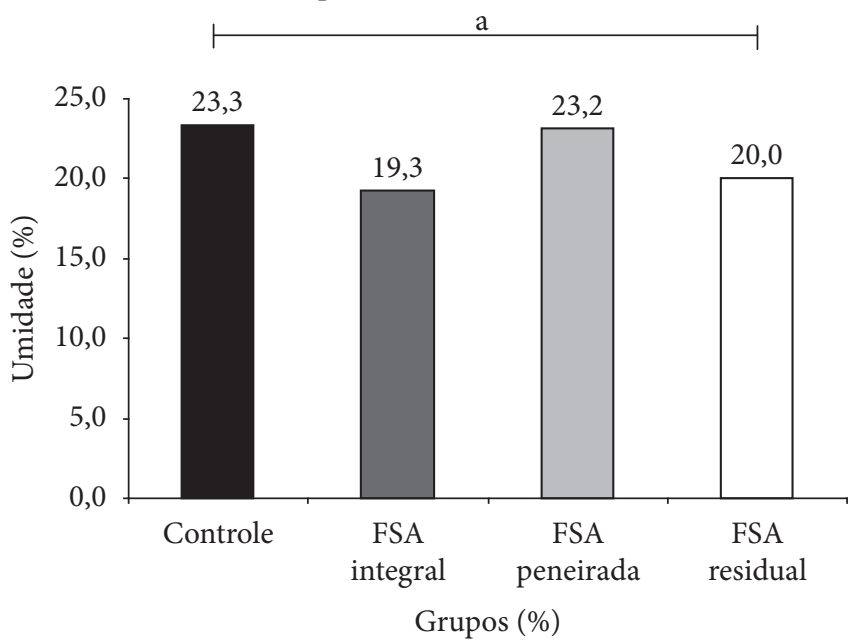

Figura 3. Percentuais médios da umidade do material fecal dos animais. Não houve diferença significativa entre os grupos $(\mathrm{p}>0,05)$.

Tabela 6. Quantidade média excretada de fibra insolúvel (g) nos tempos inicial (T1) e final (T5) do experimento.

\begin{tabular}{lcccc}
\hline \multirow{2}{*}{$\begin{array}{c}\text { Tempos } \\
\text { experimentais }\end{array}$} & \multicolumn{2}{c}{ Teor de fibra insolúvel (g) excretada nas fezes secas } \\
\cline { 2 - 5 } & & Controle & \multicolumn{3}{c}{$\begin{array}{c}\text { Experimental farinha de } \\
\text { semente de abóbora }\end{array}$} \\
\cline { 2 - 5 } & & Integral & Peneirada & Residual \\
\hline Inicial (T1) & $1,25^{\mathrm{c}}$ & $2,44^{\mathrm{ab}}$ & $2,35^{\mathrm{b}}$ & $3,25^{\mathrm{a}}$ \\
Final (T5) & $1,46^{\mathrm{c}}$ & $3,08^{\mathrm{ab}}$ & $2,68^{\mathrm{b}}$ & $3,71^{\mathrm{a}}$ \\
\hline
\end{tabular}

Médias seguidas de letras diferentes na mesma linha diferem estatisticamente entre si a $5 \%$ pelo teste de Tukey.
Ressalta-se também, a diferença absoluta do teor de fibra insolúvel excretada entre os grupos experimentais, sendo estatisticamente significante $(\mathrm{p}<0,05)$ para os animais que receberam dieta com FSA residual em relação aos que receberam dieta com FSA peneirada. Associado a tal fato, verificamos que os animais do grupo FSA residual foram os que tiveram maior peso fecal seco, cujo valor foi significativo nos tempos T2, T3 e T5 (Tabela 5) do experimento.

Conforme a Tabela 6, o tempo experimental T1 já foi capaz de expressar o teor de fibra insolúvel excretada na matéria fecal, à medida que diferenças $(\mathrm{p}<0,05)$ entre o grupo controle e experimentais, submetidos às FSAs, foram identificadas e também mantidas ao final do experimento (T5).

Os resultados obtidos no trabalho demonstraram maior quantidade de matéria fecal excretada, associada à maior quantidade de fibra insolúvel excretada (Tabelas 5 e 6) evidenciando a influência física da fibra alimentar das FSAs, sobretudo da FSA residual.

\subsection{Análise morfológica do material fecal}

O material fecal ao microscópio eletrônico de varredura (MEV) apresentou diferenças morfológicas (Figuras 4a, 4b e 4c). A presença de estruturas fibrosas nas fezes dos animais experimentais é um indicativo da resistência das frações fibra alimentar presentes na farinha de semente de abóbora, ao processo digestivo e fermentativo bacteriano.

Os grupos de animais submetidos às FSAs apresentaram diferenças perceptíveis ao $\mathrm{MEV}$, sobretudo o material fecal proveniente dos animais alimentados com FSA peneirada (Figura 4b).

As características morfológicas foram mais uniformes entre o material fecal dos grupos FSA integral e FSA residual, demonstrando partículas maiores do resíduo vegetal, enquanto o grupo submetido à FSA peneirada revelou em sua micrografia partículas menores e em maior número, devido à fração vegetal (endosperma) predominante nesta farinha.

Este resultado reforça e relaciona as menores quantidades absolutas de matéria fecal e de fibra insolúvel nas fezes encontradas para o grupo FSA peneirada (Figura 4b), conforme demonstrado nas Tabelas 5 e 6.

\subsection{Cécum e material cecal}

O estudo do apêndice cecal (Figura 5) demonstrou que os animais submetidos às rações controle e experimentais (FSAs) apresentaram respostas homogêneas para os parâmetros do cécum, embora os pesos cecais dos animais submetidos às rações com FSAs tenham sido superiores, indicando o efeito fisiológico dessas frações de fibras, como demonstrado na Tabela 5.

A Figura 5 demonstra que os grupos controle e FSA peneirada apresentaram $\mathrm{pH}$ de 7,1 , já os grupos experimentais FSAs integral e residual apresentaram $\mathrm{pH}$ de 6,9 e 6,8, respectivamente. Esta diferença de resposta do cécum pode ser explicada pelo maior teor de fibras insolúvel presente nestas rações. A fração insolúvel, por acelerar o trânsito intestinal, disponibiliza subs- 

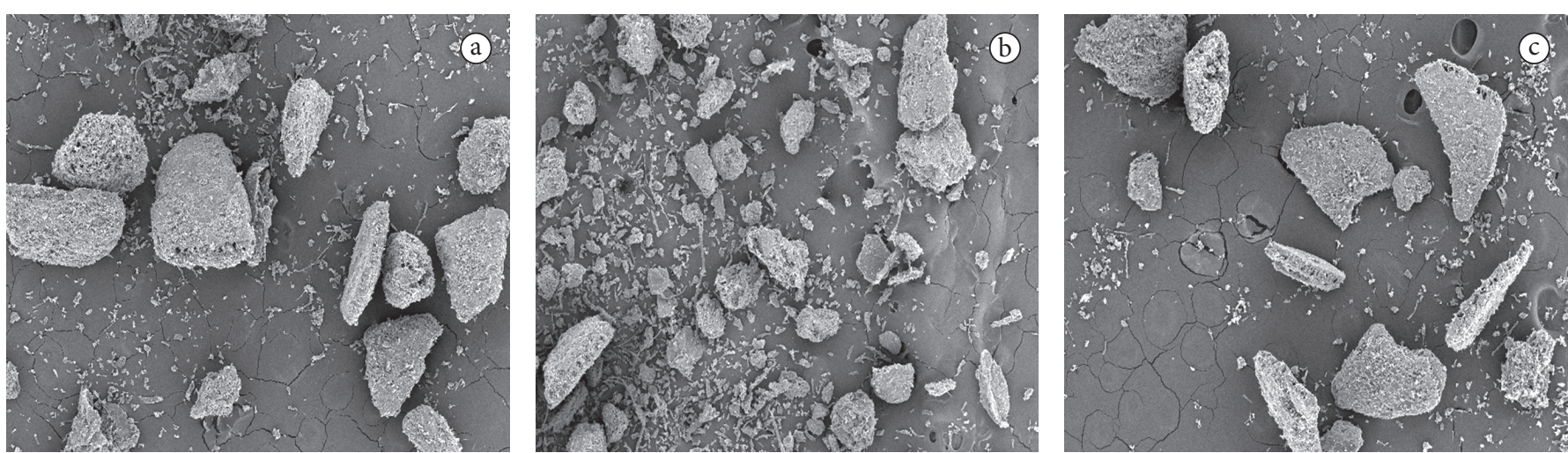

Figura 4. Micrografia de amostra de fezes ao MEV dos grupos: a) FSA integral; b) peneirada; e c) residual. Aumento de 43x.

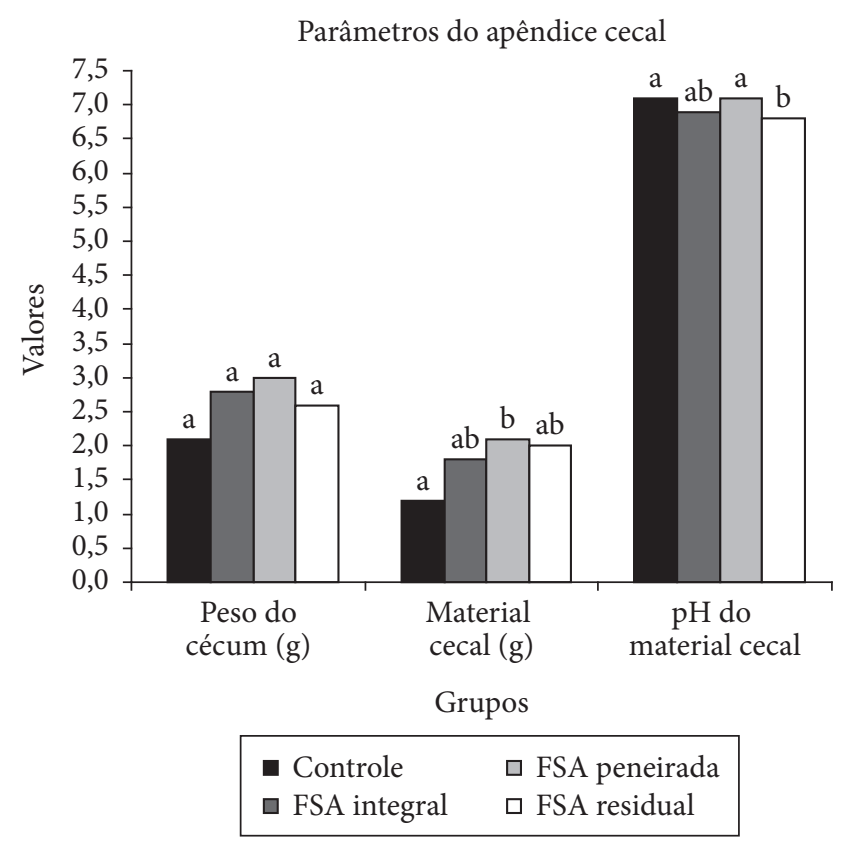

Figura 5. Peso, material e $\mathrm{pH}$ do cécum. Letras iguais acima das barras não caracterizam diferença entre os grupos $(\mathrm{p}>0,05)$

tratos à fermentação bacteriana contribuindo para o declínio ou redução do pH do conteúdo cecal (MONTEIRO, 2005).

\section{Conclusões}

As Farinhas de Semente de Abóbora (FSAs) integral, peneirada e residual apresentaram teores elevados de proteína, lipídios e fibra insolúvel.

As rações experimentais adicionadas de FSAs não alteraram o consumo alimentar e ganho ponderal dos ratos.

O maior teor de fibra proveniente das FSAs nas rações experimentais aumentou o peso e o volume fecais, sendo constatada uma relação diretamente proporcional entre a quantidade de fibra insolúvel excretada e o peso fecal, destacando-se o grupo FSA residual dos demais grupos experimentais.

O efeito laxativo proporcionado pela fibra insolúvel presente na semente de abóbora reforça a necessidade de se estudar fontes vegetais, comuns ao consumo humano, ou alternativas, que até então eram descartadas.

Os resultados do estudo indicam o potencial biológico da semente de abóbora no incremento de produtos alimentícios como fonte de fibra alimentar. Descobertas como a deste estudo contribuem não só para o meio científico, como também trazem impacto econômico e social.

\section{Agradecimentos}

O autor agradece à Coordenação de Aperfeiçoamento de Pessoal de Nível Superior - CAPES, pela concessão de bolsa de estudo (mestrado).

\section{Referências bibliográficas}

CANDIDO, L. M. B.; CAMPOS, A. M. Alimentos funcionais: Uma revisão. Boletim da SBCTA, v. 29, n. 2, p. 193-203, 1995.

DEL-VECHIO, G. et al. Efeito do tratamento térmico em sementes de abóboras (Cucurbita spp.) sobre os níveis de fatores antinutricionais e/ou tóxicos. Ciência e Agrotecnologia, v. 29, n. 2, p. 369-376, 2005.

EL-ADAWY, T. A.; TAHA, K. M. Characteristics and composition of watermelon, pumpkin, and paprika seed oils and flours. Journal Agricultural and Food Chemistry, v. 49, n. 3, p. 1253-1259, 2001.

ESUOSO, K. et al. Chemical composition and potential of some underutilized tropical biomass. I: fluted pumpkin (Telfairia Occidentalis). Food Chemistry, v. 61, n. 4, p. 487-492, 1998.

FREITAS, K. C. et al. Efeito da fibra do polissacarídeo de soja no peso e na umidade das fezes de ratos em fase de crescimento. Jornal de Pediatria, v. 80, n. 3, p. 183-188, 2004.

GIUNTINI, E. B.; LAJOLO, F. M.; MENEZES, E. W. Potencial de fibra alimentar em países ibero-americanos: alimentos, produtos e resíduos. Archivos Latinoamericanos de Nutrición, v. 53, n. 1, p. 14-20, 2003.

HADDAD, A. et al. Técnicas básicas de microscopia eletrônica aplicadas as ciências biológicas. Wanderley de Souza. (Ed.). Rio de Janeiro: Sociedade Brasileira de Microscopia, 1998. p. 179.

IAL - INSTITUTO ADOLFO LUTZ. Normas analíticas do Instituto Adolfo Lutz. Métodos químicos e físicos para análise de alimentos. 3 ed. São Paulo, 1985.

JENKINS, D. J. A. et al. Viscous dietary fibre and metabolic effects. Clinical Nutrition Supplements, v. 1, n. 2, p. 39-49, 2004. 
JONES, D. B. Factores for converting percentages of nitrogen in foods and feeds into percentage of protein. $22 \mathrm{ed}$. United States: Departament of Agriculture, 1941.

MANSOUR, E. H. et al. Nutritive value of pumpkin (Cucurbita pepo kakai 35) seed products. Journal of Science Food Agriculture, v. 61, n. 1, p. 73-78, 1993.

MATUDA, T. G.; MARIA NETO, F. Caracterização química parcial da semente de jatobá-do-cerrado (Hymenaea stigonocarpa Mart.). Ciência e Tecnologia de Alimentos, v. 25, n. 2, p. 353-357, 2005.

MENDEZ, M. H. M. et al. Método da fibra detergente neutro modificado para amostras ricas em amido. Ciência e Tecnologia de Alimentos, v. 5, n. 2, p. 123-131, 1985.

MONDINI, L.; MONTEIRO, C. A. Mudanças no padrão de alimentação da população urbana brasileira (1962- 1988). Revista de Saúde Pública, v. 28, n. 6, p. 433-439, 1994.

MONTEIRO, C. Diferentes proporções de fibra insolúvel e solúvel de grãos de aveia sobre a resposta biológica de ratos. Santa Maria, 2005. 42 p. Dissertação - (Mestrado em Ciência e Tecnologia de Alimentos), Universidade Federal de Santa Maria.

MOURE, A. et al. Physico-chemical, functional and structural characterization of fiber from defatted Rosa rubiginosa and Gevuina avellana seeds. Journal of the Science of Food and Agriculture, v.84, n.14, p.1951-1959, 2004.

PACHECO, M. T. B.; SGARBIERI, V. C. Fibra e Doenças Gastrointestinais. In: LAJOLO, F. M. et al. Fibra dietetica em Iberoamerica. Tecnologia y salud: obtencion, caracterizacion, efecto fisiologico y aplicación en alimentos. São Paulo: Varela, 2001. cap. 28, p. 385-397.

PHILIPPI, S. T. Tabela de composição de alimentos: suporte para decisão nutricional. 2 ed. São Paulo: Atheneu, 2002.
PIMENTEL-GOMES, F. A estatística moderna na pesquisa agropecuária. Piracicaba, São Paulo: Ed. F. Pimentel-Gomes, 1984.

RAUPP, D. S. et al. Propriedades funcionais-digestivas e nutricionais de polpa-refinada de maçã. Scientia Agricola, v. 57, n. 3, p. 395-402, 2000

RAUPP, D. S. et al. Digestive and functional properties of a partially hydrolyzed cassava solid waste with high insoluble fiber concentration. Scientia agricola, v. 61, n. 3, p. 286-291, 2004.

REEVES, P. G. et al. AIN-93 purified diets for laboratory rodents: final report of the American Institute of Nutrition and hoc writing Commitee on the reformulation of the AIN-76. A rodent diet. The Journal of Nutrition, v. 123, n. 11, p. 1939-1951, 1993.

RODRÍGUEZ, R. et al. Dietary fibre from vegetable products as source of functional ingredients. Trends in Food Science \& Technology, v. 17, n. 1, p. 3-15, 2006.

SAMANT, S. K.; REGE, D. V. Carbohydrate composition of some cucurbit seeds. Journal of Food Composition and Analysis, v. 2, n. 2, p. 149-156, 1989.

SCHNEEMAN, B. O. Fiber, inulin and oligofructose: similarities and differences. Journal of Nutrition, v. 129, n. 9, p. 1424-7, 1999.

VALLILO, M. I. et al. Caracterização química parcial das sementes de Lonchocarpus muehlbergianus Hassl. Revista do Instituto Adolfo Lutz, v. 60, n. 1, p. 17-22, 2001.

VAN SOEST, P. J. Use of detergents in the analysis of fibrous feeds I - Preparation of fiber residues of low nitrogen. Journal of the Association of Official Agricultural Chemists, v. 46, p. 825-829, 1963.

YOUNIS, Y. M.; GHIRMAY, S.; SHIHRY, S. African Cucurbita pepo L.: properties of seed and variabity in fatty acid composition of seed oil. Phytochemistry, v. 54, n. 1, p. 71-75, 2000. 